\title{
The Coupled GRACE/GIA Evaluation of the Antarctic Ice Mass Loss is Unreliable
}

\author{
A. Parker ${ }^{1 *}$ \\ ${ }^{1}$ School of Engineering and Physical Science, James Cook University, Townsville 4811 QLD, \\ Australia. \\ Author's contribution \\ All work, thoughts, interpretations are done by the author. \\ Article Information \\ DOI: 10.9734/JSRR/2015/17619 \\ Editor(s): \\ (1) Shahid Naseem, Department of Geology, University of Karachi, Pakistan. \\ Reviewers: \\ (1) Anonymous, University of Yaounde I, Cameroon. \\ (2) Anonymous, Ukraine. \\ (3) Saad Bakkali, Earth Sciences Department, Faculty of Sciences \& Techniques of Tangier, University A. Essaâdi, Morocco. \\ (4) Anonymous, University of Manitoba, Canada. \\ Complete Peer review History: http://www.sciencedomain.org/review-history.php?iid=1127\&id=22\&aid=9219
}

\section{Commentary}

Received $20^{\text {th }}$ March 2015

Accepted $21^{\text {st }}$ April 2015

Published $12^{\text {th }}$ May 2015

\section{ABSTRACT}

GRACE does not measure any ice sheet thickness but only gravity. Similarly to the computation of the global mean sea level (GMSL), the computation of the ice sheet thickness, follows a large number of assumptions. As a result, the actual inaccuracy of the Antarctic ice sheet thickness computation is much larger than any trend proposed. In other words, you can manufacture almost any result you want by using the noisy raw GRACE signal and selected corrections. It is however the further Glacial Isostatic Adjustment (GIA) correction that ultimately produces the reducing Antarctic ice sheet thickness, similarly to the rising Global Mean Sea Level (GMSL). This result is contradicted by other more reliable experimental results as the expanding sea ice extension and the cooling surface air temperature.

Keywords: Antarctica; ice thickness; sea ice extension; temperature; modeling; measurements. 


\section{INTRODUCTION}

While the general understanding of the Antarctic climate offers cooling temperatures and expanding sea ices, [1] propose modelling results contradicting this understanding without even mentioning the other data and analyses, and also downplaying the GRACE result huge inaccuracies making their ice thickness computation much less reliable than the contrasting results for temperatures and sea ice extension.

Antarctica has temperatures so low that over the most part of the region ice melting is simply impossible, as the temperature is always below $0^{\circ} \mathrm{C}$ and on average $-7^{\circ} \mathrm{C}$. It is only over the Antarctica Peninsula that protrudes towards South America that temperatures are little bit larger, about $-5^{\circ} \mathrm{C}$ on average, and in a couple of months per year there may also be ice melting. What else could be melting are the huge ice shelves that extend from the coast, even if it is unlikely and unproven that the temperatures of the deep oceans below are increasing.

GRACE is a system based on the Earth gravity. If some ice sheet melt, then the gravity directly above it changes and this may change the orbit of a satellite that passes over head. A satellite orbiting above a region of reducing mass experiences a reduced gravity acceleration and therefore has a tendency to increase the altitude and reduce the speed. This orbital effect is what is used by GRACE.

The raw GRACE signal is, as expected, very noisy, and the Antarctic ice thickness is not the raw GRACE signal, but the result of a double computation, one based on GRACE, the other completely decoupled. As soon as a vertical top ice boundary position is computed from GRACE, then there is the issue of computing the vertical bottom ice boundary position. The land beneath is lifting because of the post glacial rebound. This motion is not measured, but computed by a glacial isostatic adjustment (GIA) model that is everything but accurate. This result of two inaccurate computations cannot return a precise estimation of the Antarctic ice sheet thickness.

\section{THE GRACE COMPUTATION OF ICE THICKNESSIS NOT RELIABLE}

The GRACE estimations are not measurements but actually computations where starting from a noisy signal - the ice upper surface position - the ice thickness is then computed by subtracting the GIA land underneath vertical position - the ice lower surface position - and this result has huge inaccuracies that are being downplayed in the commented paper. Following the principle that any imperfect measure of a climate parameter become perfect as soon as it proves the IPCC narrative of melting ices, rising seas, reducing rainfalls and warming temperatures is true, the authors do not discuss the contrasting results obtained with other techniques that have much better accuracy for temperature and sea ice extent, and do not discuss seriously the accuracy limits of their technique, where the error is much larger than the trend.

After a careful selection of the references to consider - mostly analyses based on direct or indirect climate modelling results - and to neglect - all the analyses built on true measurements, according to [1] "numerous sources" have already confirmed that Antarctica is losing ice at a quickening rate. Hence, they propose a novel and more accurate "evidence". This ultimate evidence is based on the results of the Gravity Recovery and Climate Experiment (GRACE), plus the modelled glacial isostatic adjustment (GIA). According to their purely computational exercise, "over the period 2003-2014West Antarctica has lost ice mass at a rate of $121 \pm 8 \mathrm{Gtons} /$ year, with an acceleration of the ice mass loss of $-18 \pm 5$ Gtons/year ${ }^{2}$ along the Amundsen Sea coast, to produce an overall ice mass loss of $-92 \pm 10$ Gtons/year for Antarctica".

If we do consider the information available from multiple other sources for Antarctica, again of expanding sea ice and cooling temperature, we wonder how the authors and the reviewers could ignore the existence of such a large amount of empirical evidence to support one more purely computational exercise.

Measurements and reconstructions are not all the same quality. In the specific, the temperature measurements are the most reliable. Then, the $x-$ $y$ measurements of the sea ice extension have relatively good reliability. Both these results show, again, cooling temperatures and expanding sea ices. Finally, we came to the less reliable result, the $z$ ice thickness that strongly depends on the estimation of the position of the top and bottom ice boundaries. This result should not be proposed as the only evidence.

GRACE is certainly an interesting technique but still in its test stage. Sea levels are another 
possible application of GRACE not requiring an extra information impossible to measure as it is the case of the ice thickness. The first sequence of GRACE gave slightly lowering global mean sea levels. As revealed by [2], this slightly reduction was then immediately corrected to $a+2$ $\mathrm{mm} /$ year global mean sea level (GMSL) rise with just one more round of corrections between the raw signal and the final product claiming the global isostatic adjustment (GIA) was the reason.

With the space gravimeter observations from GRACE it is possible to record changes in the ocean water mass which approximate the mean global sea level changes. Fig. 1 presents this result. The raw data show a slight lowering of the GMSL. Inferring a very questionable global isostatic adjustment (GIA) correction, [3] established a corrected sharply increasing rate. The difference is significant. The uncorrected data suggest the relative sea level is slightly reducing. The corrected data tell us the absolute sea level is rising significantly. Without the correction, there is no GMSL rise.

The accuracy on the $z$ position of the top ice boundary very unlikely suffer of errors less than $\pm 2 \mathrm{~mm} /$ year, as this is the error of the much more evolved Global Positioning System (GPS) monitoring of fixed GPS domes (see the SONEL and JPL results for the same domes, [4] and [5]). The accuracy of the $z$ position of the land underneath that is based on a GIA computation is even less accurate (see for example the SONEL and JPL results for the locations where [6] provides the GIA computational results). The GPS based vertical velocities computed by SONEL or JPL for many GPS domes worldwide are very far from the GIA simplistic description with differences of millimeters per year. The GIA correction is indeed very questionable as already noted by [7]. A comparison of GPS and GIA results for the key sites of Antarctica is proposed in the Appendix.

The global isostatic adjustment, or GIA, is a model, in which some data are in support (see for example [8]) and other data are in contradiction (for example [9]). The latest SONEL and JPL results are also not that supportive for the GIA computation. GIA corrections have been applied to tide gauges, sea level records, satellite altimetry, Ocean and ice mass changes. It seems that without the GIA corrections there is very little room left for a global sea level rise or a reduction of the ice mass [2].

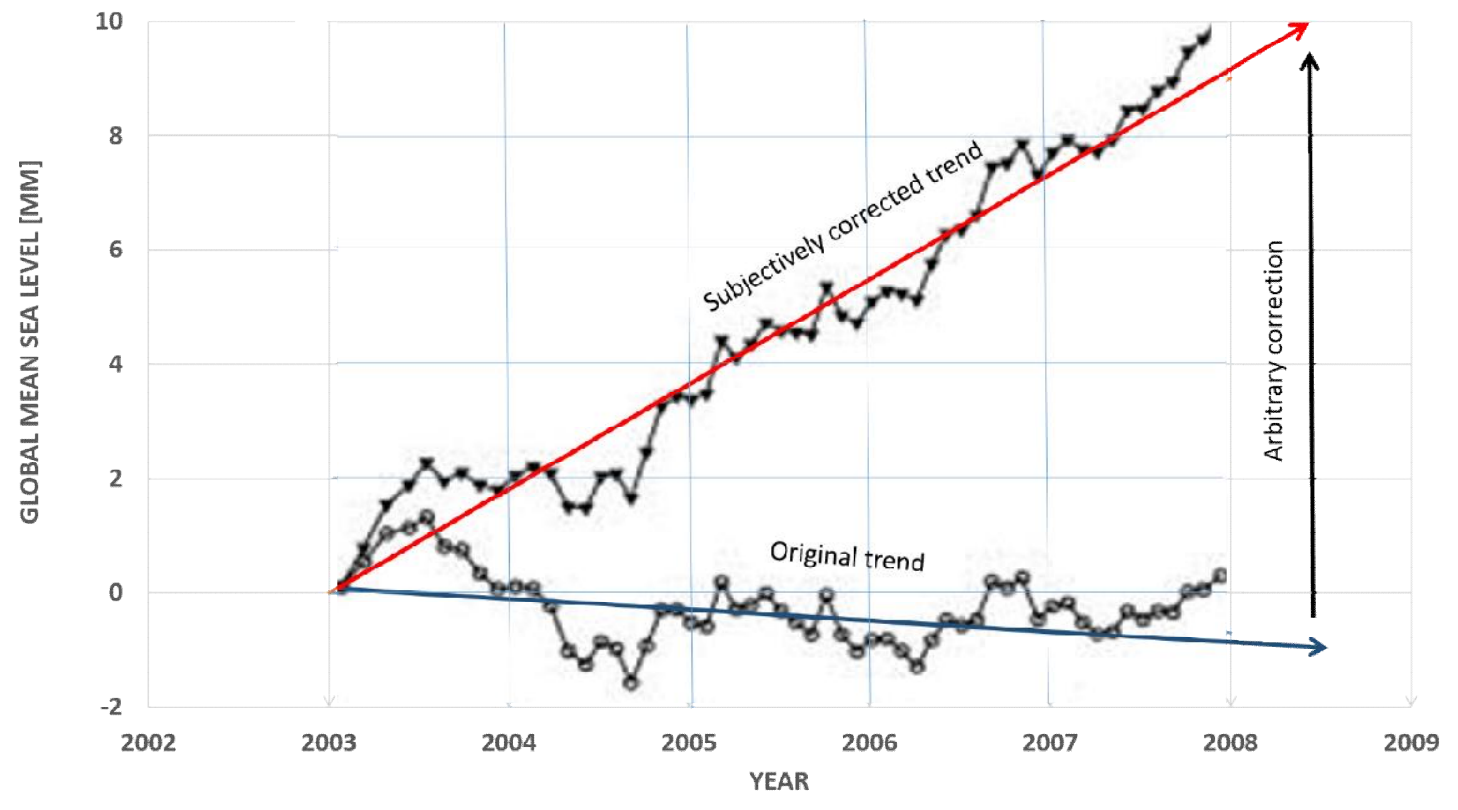

Fig. 1. The space gravimeter readings from the GRACE satellites of the global mean sea level and their corrected values. The raw data show a slight lowering. By introducing a very questionable Global Isostatic Adjustment (GIA) correction, [3] established a significant increasing rate. The difference is significant, as the corrected data suggest a trend completely different from the raw data. The raw data have not been shown hereafter. The trends are computed from the data proposed in [3] 
Fig. 2 presents the Southern Hemisphere Sea Ice Area Anomaly from [10]. The sea ice area is increasing. Fig. 3 presents the Southern Polar Lower Troposphere Temperature from [11]. The temperature is decreasing. The ice thickness should certainly not be reducing while the temperatures are cooling and the sea ice is expanding. The data are downloaded from [10] and [11] respectively and analyzed here.

A much ticker than the expected Antarctic ice is also confirmed by novel and more accurate in situ observation [12]. Their three-dimensional floe-scale maps of sea-ice draft for ten floes was compiled from two springtime expeditions by an autonomous underwater vehicle to the nearcoastal regions of the Weddell, Bellingshausen, and Wilkes Land sectors of Antarctica. The results show that the floes are much thicker and more deformed than reported by drilling and ship based measurements. The ice thickness in the near coastal and interior pack may therefore be under estimated by existing in situ assessments and the Antarctic sea ice may be thicker than believed before.

The combined GRACE-GIA result is highly speculative, and certainly more to be regarded as a poor computation than a truly accurate measurement. The inaccuracy and unreliability does not emerge at all in the commented work that simply ignores the existence of the other measurements and avoids to mention the actual error of their procedure is orders of magnitude larger than their claim.

If we do consider a reference area for Antarctica of $14 \cdot 10^{6} \mathrm{Km}^{2}$ or $1.4 \cdot 10^{13} \mathrm{~m}^{2}$ and a reference density for ice of $916.7 \mathrm{Kg} / \mathrm{m}^{3}$, or $0.9167 \mathrm{tons} / \mathrm{m}^{3}$, an error of even $\pm 1 \mathrm{~mm} /$ year on the evaluation of the difference between the GRACE based computation of the upper ice boundary movement and the GIA computation of the lower ice boundary movement, by far much less accurate than that, then produce an error on the estimation of the ice loss of many orders of magnitude larger than the claimed \pm 10 Gtons/year, that is an outrageously small number.

Once more the problem of global warming analyses are the orders of magnitudes, with trends much larger than the legitimate (and sometimes opposite to any logic and other experimental evidence) and errors much smaller than reasonable and the selling as experimental evidence of results that have a very limited experimental support.

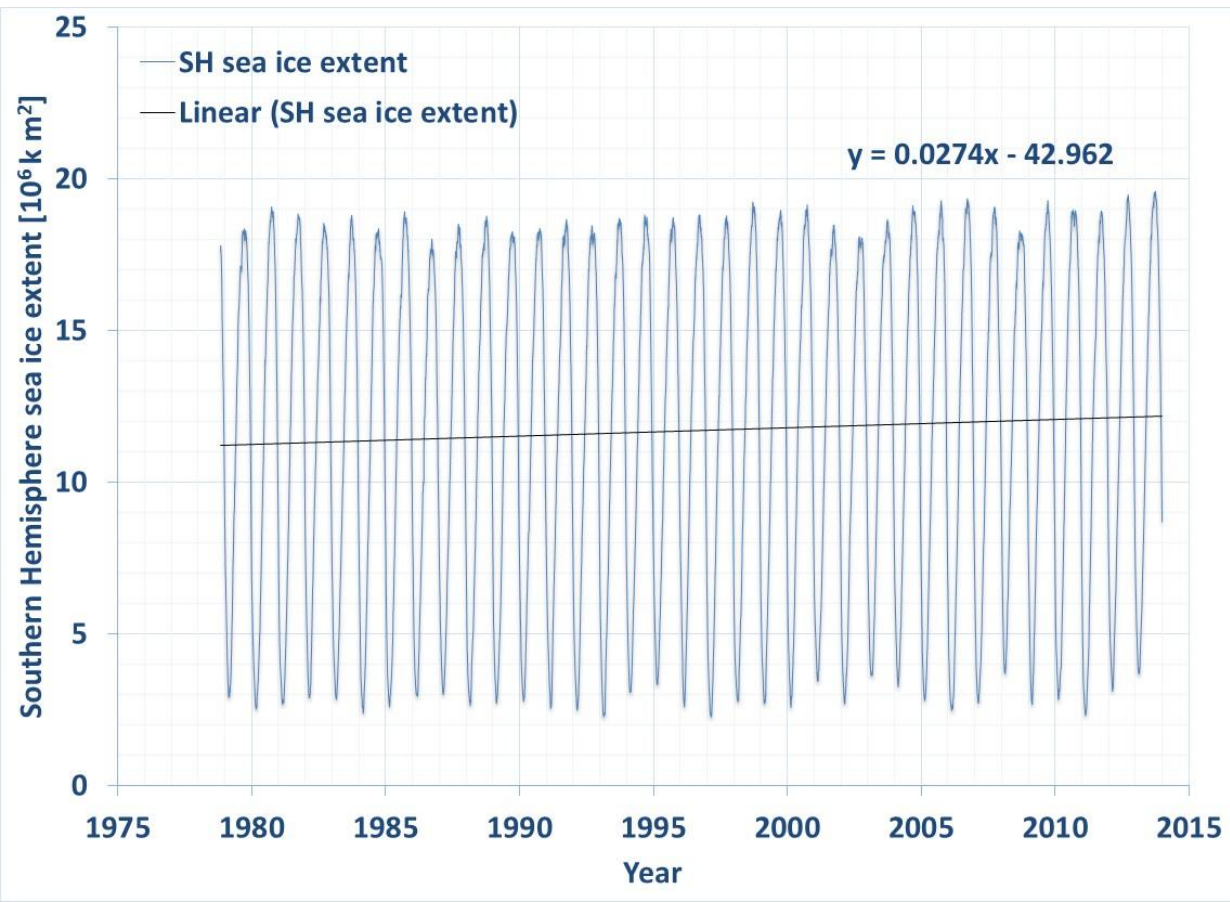

Fig. 2. Southern hemisphere sea ice area anomaly. Source data are downloaded from [10]. The sea ice area is increasing 


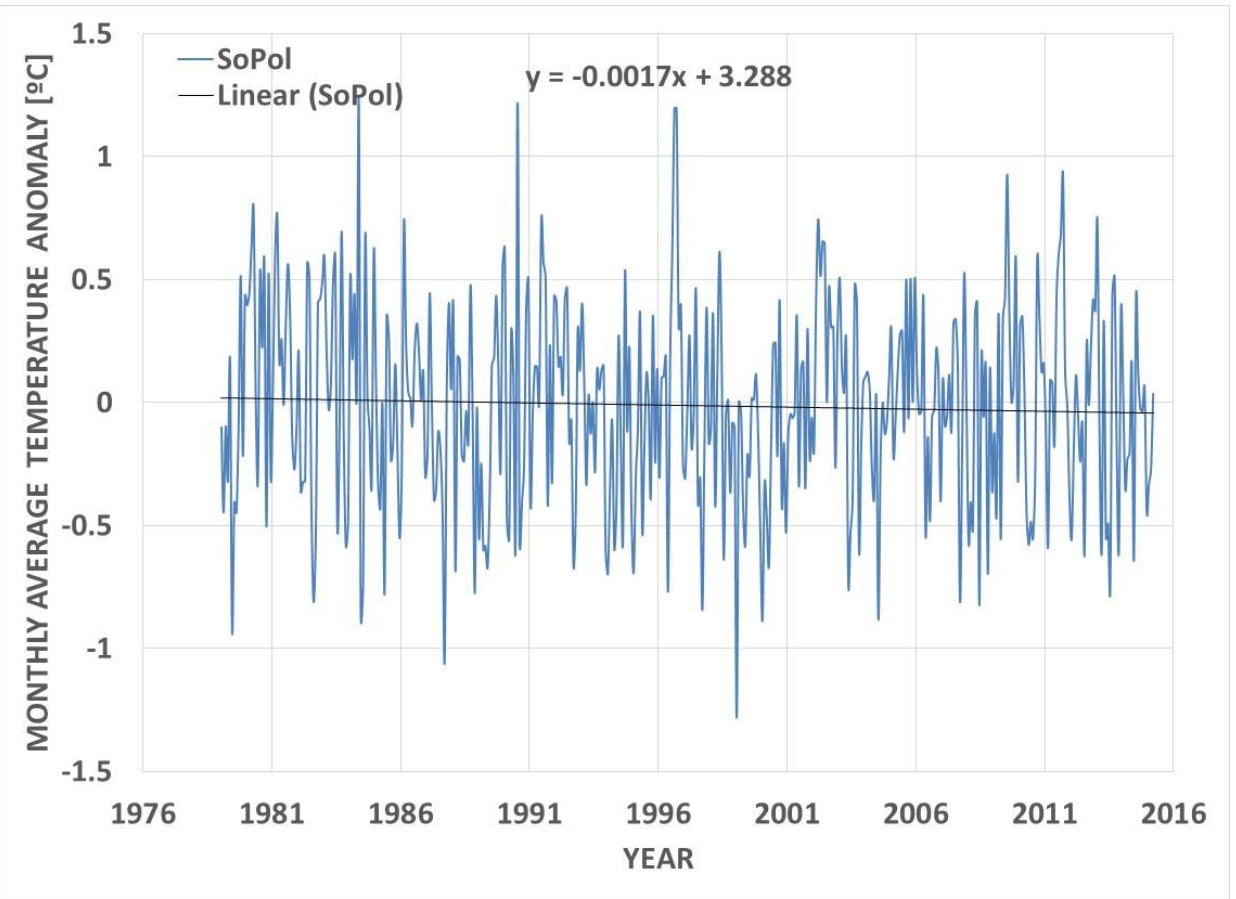

Fig. 3. Southern polar lower troposphere temperature. Source data are downloaded from [11]. The temperature is decreasing

\section{CONCLUSION}

GRACE is a procedure still under development that suffers of two major sources of inaccuracies, the procedure to compute the vertical position of the top ice boundary from the raw mostly noisy satellite signal, that suffer of major uncertainties and somewhat arbitrary corrections, and the procedure that computes the bottom ice boundary with a GIA model, that should never ever have been used for the purpose being only qualitative.

As for the specific of Antarctica the GIA computations certainly overrate the land uplift, not only the error is much larger than the trend, but very likely the trend is of increasing ice thickness rather than reduction, as compatible with all the other measurements. The overall Antarctic ice mass loss since January 2003 is definitively not $-92 \pm 10$ Gtons/year as the actual uncertainty on this result is many order of magnitude larger than the trend and the minus sign is increasingly suspicious.

\section{COMPETING INTERESTS}

The author has no financial and personal relationships with other people or organizations that could inappropriately influence (bias) their work.

\section{REFERENCES}

1. Harig C, Simons F. Accelerated West Antarctic ice mass loss continues to outpace East Antarctic gains, Earth plan. Sci. Let. 2015;415:134-141.

2. Mörner N. THE great Sea-level Humbug. There Is No Alarming Sea Level Rise!, 21st Century Science \& Technology, Winter 2010/2011. 2011;12-22.

3. Cazenave K, Dominh S, Guinehut E, Berthier W, Llovel G, Rammien M, Ablain, Larnicol G. Sea level budget over 20032008: A reevaluation from GRACE space gravimetry, satellite altimetry and Argo. Global Planetary Change. 2009;65:83-88.

4. SONEL Vertical land movement; 2015. Available:http://www.sonel.org/-Verticalland-movement-estimate-.html?lang=en on April 20, 2015.

5. NASA Jet Propulsion Laboratory JPL GPS time series; 2015.

Available:http://sideshow.jpl.nasa.gov/post/ series.html on April 20, 2015.

6. Peltier WR. Predictions for ICE-5G (VM2 L90) model (version 1.3) for PSMSL tide 
gauge sites (in ASCII format); 2012. Available:http://www.atmosp.physics.utoro nto.ca/ peltier/data.php on April 20, 2015.

7. Mörner N. Sea level changes past records and future expectations. Energy \& Environment. 2013;24(3\&4).

8. Peltier WR. Post glacial variations in the level of the sea: implications for climate dynamics and solid-earth geophysics. Rev. Geophysics. 1998;36:603-689.

9. Mörner N. Sea level changes and crustal movements with special aspects on the Mediterranean. Z. Geomorph. N.F. 2005;137(Suppl.):91-102.

10. United States Government National Snow and Ice Data Center NSDIC. Sea ice concentrations from Nimbus-7 SMMR and
DMSP SSM/I passive microwave data; 2015.

Available:http://nsidc.org/data/nsidc0051.html on April 20, 2015.

11. Remote sensing systems RSS Microwave Sounding Units MSU global temperatures; 2015.

Available:http://data.remss.com/msu/graph ics/TLT/time series/RSS TS channel TL T Southern\%20Polar Land And Sea v0 3 3.txt on April 20, 2015.

12. Williams G, Maksym T, Wilkinson J, Kunz C, Murphy C, Kimball P, Singh H. Thick and deformed Antarctic sea ice mapped with autonomous underwater vehicle. Nature Geoscience. 2015;8(1):61-67. 


\section{APPENDIX - GPS AND GIA VERTICAL VELOCITIES OF KEY SITES IN ANTARCTICA}

For Antarctica, we may consider the SONEL [4] ulr5 vertical velocities for the local GPS domes (data are given below as site, latitude, longitude, length of the GPS time series, percentage of data in the time series, GPS vertical velocity in $\mathrm{mm} /$ year, GPS vertical velocity uncertainty in $\mathrm{mm} / \mathrm{year}$ ):

- CAS1, -66.2833, 110.5197, 15.98, 88.5, 1.32, 0.85

- $\quad$ MAW1, -67.6047, 62.8707, 15.84, 98.4, $-\mathbf{0 . 1 1}, 0.21$

- $\quad$ DAV1, $-68.5773,77.9726,15.98,68.6,-0.85,0.52$

- SYOG, -69.0069, 39.5837, 15.78, 95.6, 2.04, 0.44

- MCM4, - $77.8383,166.6693,15.92,99.5,-0.6,0.69$

The error or uncertainty mentioned above is only the statistical fitting error. The actual error is much larger than that, possibly $\pm 1-2 \mathrm{~mm} /$ year.

On the basis of the same global positioning time series, by only using a slightly different method to handle the drifts in the satellites' orbits, JPL [5] proposes still significantly different velocities and fitting uncertainties (data are given below in $\mathrm{mm} /$ year):

- CAS1, 1.630, 0.224

- MAW1, $-0.247,0.247$

- DAV1, $-0.903,0.384$

- SYOG, 0.572, 0.201

- MCM4, 1.186, 0.309

$-$

If we do consider next the latest GIA computations by Peltier [6], Predictions for ICE-5G (VM2 L90) model (version 1.3) for the same locations in Antarctica, we do have the following vertical velocities (data are provided below as location, latitude, longitude \& rates of vertical motion in $\mathrm{mm} / \mathrm{year}$ over different time windows, obviously with no error mentioned):

- CASEY,-66.267, 110.517, 1886, 999055, -0.64, -0.62,-0.63

- $\quad$ MAWSON, $-67.600,62.883,1814,999051,2.42,2.27,2.34$

- DAVIS, $68.450,77.967,1847,999046, \mathbf{0 . 0 0},-\mathbf{0 . 0 2},-\mathbf{0 . 0 1}$

- SYOWA, $-69.000,39.567,1396,999041, \mathbf{0 . 1 8}, \mathbf{0 . 1 6}, \mathbf{0 . 1 7}$

- MCMURDO SOUND, $-74.750,164.500,1048,999061,1.37,1.31,1.34$

By comparing the above land velocities we may figure out that the differences are significant even in the very few key comparison sites. Which are the "true" values of the vertical velocities for these few selected locations is difficult to say. Certainly, this is impossible within an accuracy of the nanometer per year.

(C) 2015 Parker; This is an Open Access article distributed under the terms of the Creative Commons Attribution License (http://creativecommons.org/licenses/by/4.0), which permits unrestricted use, distribution, and reproduction in any medium, provided the original work is properly cited.

Peer-review history:

The peer review history for this paper can be accessed here: http://www.sciencedomain.org/review-history.php?iid=1127\&id=22\&aid=9219 